\title{
Evaluation of spring barley breeding lines in a two-year multi-location experiment using some statistical methods
}

\author{
Bogna Zawieja ${ }^{1}$, Ewa Bakinowska ${ }^{2}$, Andrzej Bichoński ${ }^{3}$ \\ ${ }^{1}$ Department of Mathematical and Statistical Methods, Poznań University of Life Sciences, Wojska \\ Polskiego 28, 60-637 Poznań, Poland, e-mail: bogna13@up.poznan.pl \\ ${ }^{2}$ Institute of Mathematics, Poznań University of Technology, Piotrowo 3A, \\ 60-965 Poznań, Poland \\ ${ }^{3}$ Malopolska Breeding Company Polanowice, Zbożowa 4, 30-002 Kraków, Poland
}

\begin{abstract}
SUMMARY
In breeding experiments conducted prior to tests connected with the registration of new breeding lines of crops, pre-preliminary and preliminary trials are carried out. In this study a comparison was made among some models of analysis of variance, in relation to the selection of new breeding lines of spring barley (Hordeum vulgare L.). The aim is to determine whether the choice of model of analysis of variance may influence the choice of tested breeding lines. The trait considered was the yield in two years of trials. A more comprehensive analysis of variance model was found to be superior. It was also found that the results of analyses performed using average measurements for lines significantly differ from those obtained on the basis of all measurements. It was concluded that the type of ANOVA model used may have an impact on inferences about breeding lines. Moreover, a lack of stability in the yields of tested lines was revealed, implying the necessity of several years of trials.
\end{abstract}

Key words: breeding trials, genotype-environmental interaction, Hordeum vulgare L., multienvironment trials, yield.

\section{Introduction}

Breeding trials (most often two-year trials - pre-preliminary and preliminary) are conducted prior to the reporting of new plant breeding lines for registration tests (Allard 1999). The trials are carried out in several locations with contrasting environmental conditions (class of soil, climate). In the analyzed trials the experimental design is the same for each location; moreover, the same breeding lines are tested. Such trials can be analyzed using various models of analysis of variance, for example taking into account the whole structure of the trial (blocks, 
series and locations) or performing separate analyses in each location or series. On the basis of the results obtained, the new breeding lines are assessed for suitability for registration testing. Hence the appropriate analysis of these trials will enable the selection of the most valuable breeding lines. In this study, the results of applying various models of statistical analysis, based on ANOVA (Smith et al. 2005), are considered. Both the coefficient of rank correlation and coefficient of agreement (Stehman 1992, Wieringen and Heuvel 2005) were used as measures of the similarity of results obtained by the models in a given year and also between years. The first of these measures (correlation coefficient of rank) was used to compare the ranking of objects in terms of improved average yield, the second (coefficient of agreement) to compare the methods in terms of the significance of the contrasts of the tested breeding lines with the controls. Some of the ANOVA models allowed the yield of breeding lines to be assessed either separately in the different environments (then the means are taken into consideration) or taking into account genotype-environment interaction. In this study, trials of breeding lines of spring barley (Hordeum vulgare L.) were analyzed in respect of yield [dt/ha]. The assessment of breeding lines of malting barley in terms of several traits was previously considered by Bystry et al. (2005).

The objective was to ascertain the impact of the ANOVA model used on the choice of genotypes. A further aim was to identify a method of analysis of breeding data enabling the detection of differences among tested breeding lines and controls.

\section{Material and methods}

The results of pre-preliminary (PW) and preliminary (WST) breeding trials on spring barley, conducted in the years 2011 and 2012 at several locations, were considered. In the pre-preliminary trials, at each of five locations, three independent series of experiments were performed in randomized incomplete block designs with three replications. Two series of trials (denoted PPI, PPII) were performed on 38 fodder barley breeding lines, and one (PB) was performed on 41 
malting barley lines. The preliminary trials were conducted in two series at six locations. In the first series (WP) 45 breeding lines of fodder barley were tested, and in the second (WB) 28 breeding lines of malting barley were tested. From the total number of genotypes 44 new breeding lines were tested in both years of the study. All trials were conducted in a balanced incomplete block design with three replications (the size of incomplete blocks ranged from 6 to 8). One trait was considered, namely yield $\left[\mathrm{dtha}^{-1}\right]$. Three control varieties were used.

Several mixed models of analysis of variance were applied, and a ranking of the studied breeding lines was established on the basis of improved averages (predicted least squares means). Analyses of variance were conducted separately for each series of trials, and then the results were jointly ranked. Analysis of variance in the form $y_{i j}=\mu+\tau_{i}+\beta_{j}+e_{i j}$ was performed separately for each location (Elandt 1964 pp. 130-271), where $y_{i j}$ is the yield of the $i$ th genotype in the $j$ th block, $\mu$ is the overall mean, $\tau_{i}$ is the fixed effect of the $i$ th genotype, $\beta_{j}$ is the random effect of the $j$ th block, and $e_{i j}$ is the random error, which is assumed to be normally distributed with mean 0 and variance $\sigma^{2}$ (model A1). Hierarchical analysis of variance was performed (Montgomery, 2000), for which it was assumed that random blocks were nested in locations. In this analysis the genotype-environment interaction (here locations means environments) was included; it takes the form $y_{i j l}=\mu+\tau_{i}+\lambda_{l}+\beta_{j}\left(\lambda_{l}\right)+\gamma_{i l}+e_{i j l}$, where $y_{i j l}$ is the yield of the $i$ th genotype in the $j$ th block in the $l$ th location, $\lambda_{l}$ is the random effect of the $l$ th location, $\gamma_{i l}$ is the random effect of interaction, $e_{i j l}$ is the random error, and other symbols are defined as in model A1 (model A2). The genotype means from locations were taken as the data for analysis. In this case the analysis of variance model $y_{i j}=\mu+\tau_{i}+\lambda_{l}+e_{i l}$ was used (A3). Finally, ordinary means were considered (A4).

In the various models of analysis of variance the effects of different factors were taken into account. The effect of blocks was considered in the case of A1, the effects of locations and blocks in the case of A2, and the effect of locations in the case of A3. In A4 no factor was included. It should be noted that in each of the trial series different breeding lines were studied (only the controls were the 
same), thus the analysis of all series jointly and separately should not have a major impact on the choice of breeding lines. In this paper all methods were applied separately for each series of trials, but the results were considered jointly.

In order to choose the best yielding breeding lines, the percentage yield relative to the average percentage for the controls was calculated using appropriate corrected means (calculated in a given model). Next ranks were established for the purpose of easier comparison of the results of various methods. Moreover, a statistical method was applied for determining contrasts among the studied breeding lines and controls.

\section{Results}

Based on analysis using model A1, highly significant differences among breeding lines were identified in almost all trials (Table 1). The differences among the three control varieties were most often not significant. The results of analysis with model A2 led to similar conclusions in the case of the PW trials (all of the factors differed significantly) with the exception of the control varieties (Table 2). Moreover, highly significant differences among locations and for genotypeenvironment interaction were identified in both the PW and WST trials. In the case of the WST trials, significant differences were also shown among the controls. On the basis of the results of analysis using model A3, significant differences were found among breeding lines, but also among the controls in the WB trial (Table 2), while non-significant differences were found among the controls in trials PPI, PPII and PB.

Since the differences among tested objects (breeding lines and controls) were significant, contrasts among breeding lines and controls could be found; because three controls were used, the contrasts of individual breeding lines relative to all controls were calculated. In the PW trials and model A1 jointly 96 lines significantly differed from the controls, in model A2 51 such lines were found, and in model A3 32 such lines. In the WST trials with model A1 60 lines significantly differed from the controls, in model A2 there were 37 such lines, 
Table 1. ANOVA A1 $p$-values (separately in each location)

\begin{tabular}{|c|c|c|c|c|c|c|c|c|c|c|c|}
\hline \multicolumn{12}{|c|}{ Fodder barley pre-preliminary trials (PPI) } \\
\hline Source & \multicolumn{2}{|c|}{ d.f. } & \multicolumn{2}{|c|}{ M1 } & \multicolumn{2}{|c|}{$\mathrm{M} 2$} & \multicolumn{2}{|c|}{ M3 } & \multicolumn{2}{|c|}{ M4 } & M5 \\
\hline $1^{*}$ & \multicolumn{2}{|c|}{20} & \multicolumn{2}{|c|}{$<.0001$} & \multicolumn{2}{|c|}{$<.0001$} & \multicolumn{2}{|c|}{0.2226} & \multicolumn{2}{|c|}{$<.0001$} & $<.0001$ \\
\hline $2^{*}$ & \multicolumn{2}{|c|}{34} & \multicolumn{2}{|c|}{$<.0001$} & \multicolumn{2}{|c|}{$<.0001$} & \multicolumn{2}{|c|}{0.0269} & \multicolumn{2}{|c|}{$<.0001$} & $<.0001$ \\
\hline $3^{*}$ & \multicolumn{2}{|c|}{2} & \multicolumn{2}{|c|}{0.7365} & \multicolumn{2}{|c|}{0.0658} & \multicolumn{2}{|c|}{0.0266} & \multicolumn{2}{|c|}{0.7945} & 0.9233 \\
\hline $4^{*}$ & \multicolumn{2}{|c|}{1} & \multicolumn{2}{|c|}{0.5838} & \multicolumn{2}{|c|}{0.1389} & \multicolumn{2}{|c|}{0.5684} & \multicolumn{2}{|c|}{0.0555} & 0.4827 \\
\hline \multicolumn{12}{|c|}{ Fodder barley pre-preliminary trials (PPII) } \\
\hline Source & \multicolumn{2}{|c|}{ d.f. } & & 11 & & 42 & & M3 & & M4 & M5 \\
\hline $1^{*}$ & & 0 & & 015 & $<.0$ & 001 & & 1887 & & 0001 & 0.0017 \\
\hline $2^{*}$ & & 4 & & 001 & $<.0$ & 001 & & 0001 & & 0109 & $<.0001$ \\
\hline $3^{*}$ & & 2 & & 852 & & 099 & & 7505 & & 6405 & 0.7518 \\
\hline $4^{*}$ & & 1 & & 072 & 0.2 & 165 & & 3426 & & 6454 & 0.9403 \\
\hline & & & $\mathrm{b}$ & irley & re- & preli & ina & ary tri & Is ( & (PB) & \\
\hline Source & & f. & & 11 & & 12 & & M3 & & M4 & M5 \\
\hline $1^{*}$ & & 7 & & 001 & & 001 & & 0768 & & 0001 & 0.0002 \\
\hline $2^{*}$ & & 7 & & 001 & & 001 & & 0001 & & 0001 & 0.0002 \\
\hline $3^{*}$ & & 2 & & 519 & & 073 & & 0812 & & 9956 & 0.3600 \\
\hline $4^{*}$ & & 1 & & 067 & & 101 & & 5628 & & 2305 & 0.9210 \\
\hline & & & & 10 & & $1 \mathrm{III}$ & ry & trials & $\overline{N P}$ & & \\
\hline Source & d.f. & & & $\mathrm{M}$ & & $\mathrm{M}$ & & $\mathrm{M}$ & & M5 & M6 \\
\hline $1^{*}$ & 20 & & 001 & $<.0$ & & $<.0$ & & 0.00 & & $<.0001$ & 0.0016 \\
\hline $2^{*}$ & 41 & & 001 & $<.0$ & 001 & $<.0$ & & $<.00$ & & $<.0001$ & 0.0007 \\
\hline $3^{*}$ & 2 & & 429 & 0.3 & 203 & 0.0 & & 0.81 & & 0.0007 & 0.2526 \\
\hline $4^{*}$ & 1 & & 353 & 0.7 & 334 & 0.2 & & 0.52 & & 0.1533 & 0.7565 \\
\hline & & & ng & arley & pre & limir & ary & trials & $\mathrm{WH}$ & & \\
\hline Source & d.f. & & 11 & $\mathrm{M}$ & & $\mathrm{M}$ & & $\mathrm{M4}$ & & M5 & M6 \\
\hline $1^{*}$ & 17 & & 001 & 0.0 & 002 & $<.0$ & & 0.00 & & 0.0031 & 0.0029 \\
\hline $2^{*}$ & 24 & & 001 & $<.0$ & 001 & $<.0$ & & 0.00 & & 0.0019 & 0.0836 \\
\hline $3^{*}$ & 2 & & 888 & 0.0 & 280 & 0.0 & & 0.38 & & 0.0302 & 0.0840 \\
\hline $4^{*}$ & 1 & & 115 & 0.3 & 519 & 0.0 & & 0.40 & & 0.2581 & 0.5326 \\
\hline
\end{tabular}

$1^{*}$ - blocks; $2^{*}$ - breeding lines; $3^{*}$ - controls; $4^{*}$ - breeding lines vs. controls; d.f.: degrees of freedom; M1-M6: locations

and in model A3 24 such lines. In model A1 35 of the 96 distinguished lines were significant in one location (of five), 31 lines were significant in two locations, 21 in three locations, 8 in four locations, and finally one breeding line was distinguished in all five locations. Similarly, in the WST trials significant differences from the controls in one location were shown for 14 lines, in two 
Table 2. ANOVA A2 (hierarchical model) and A3 (data - averages by locations) $p$-values

\begin{tabular}{lrrrrrrrrr}
\hline Source & d.f. & PPI & PPII & d.f. & PB & d.f. & WP & d.f. & WB \\
\hline A2 & & & & & & & & & \\
\hline Locations & 4 & $<.0001$ & $<.0001$ & 4 & $<.0001$ & 5 & $<.0001$ & 5 & $<.0001$ \\
Blocks (locations) & 100 & $<.0001$ & $<.0001$ & 85 & $<.0001$ & 120 & $<.0001$ & 102 & $<.0001$ \\
Treatments vs. locations & 148 & $<.0001$ & $<.0001$ & 160 & $<.0001$ & 220 & $<.0001$ & 135 & $<.0001$ \\
Breeding lines & 34 & $<.0001$ & $<.0001$ & 37 & $<.0001$ & 41 & $<.0001$ & 24 & $<.0001$ \\
Controls & 2 & .0559 & .4950 & 2 & .6623 & 2 & .0009 & 2 & $<.0001$ \\
Breeding lines vs. controls & 1 & .7360 & .5718 & 1 & .4784 & 1 & .3130 & 1 & 0.1302 \\
\hline A3 & & & & & & & & & \\
\hline Locations & 4 & $<.0001$ & $<.0001$ & 4 & $<.0001$ & 5 & $<.0001$ & 5 & $<.0001$ \\
Breeding lines & 34 & $<.0001$ & $<.0001$ & 37 & .0030 & 41 & $<.0001$ & 24 & $<.0001$ \\
Controls & 2 & .0726 & .9901 & 2 & .8695 & 2 & .2463 & 2 & .0032 \\
Breeding lines vs. controls & 1 & .6554 & .7777 & 1 & .3048 & 1 & .6247 & 1 & .4142 \\
\hline
\end{tabular}

locations for 25 lines, in three locations for 13 lines, in four locations for 6 lines, in five locations for 1 line, and 1 line differed in all six locations.

Due to the large number of tested breeding lines, only the results for genotypes most relevant to the choice of analysis of variance model will be discussed in detail. Namely, 20 breeding lines were chosen, from the lines which had been tested in both years of the trials. The choice was made in such a way that both the highest and lowest yields were included among the selected breeding lines. In the following part of the study the fodder barley lines were denoted by numbers from 4 to 73 , and malting barley lines by numbers from 74 upwards; controls were numbered from 1 to 3 .

The ranks obtained from comparing the improved averages of the lines with the average of the improved means of the controls were used for assessment of the breeding lines. The ranks obtained for the breeding lines in one year of the study are somewhat different depending on the ANOVA model (Figures 1 and 2). However, between the years, the rank differed significantly for the same models. There were few breeding lines which received a fairly high rank in both years of the study (for example lines 80, 8 and 53).

On the basis of the ranks it was possible to assess whether the yield of a given line was better or worse than the controls; the statistical significance of this difference could be assessed on the basis of contrasts between the controls and 


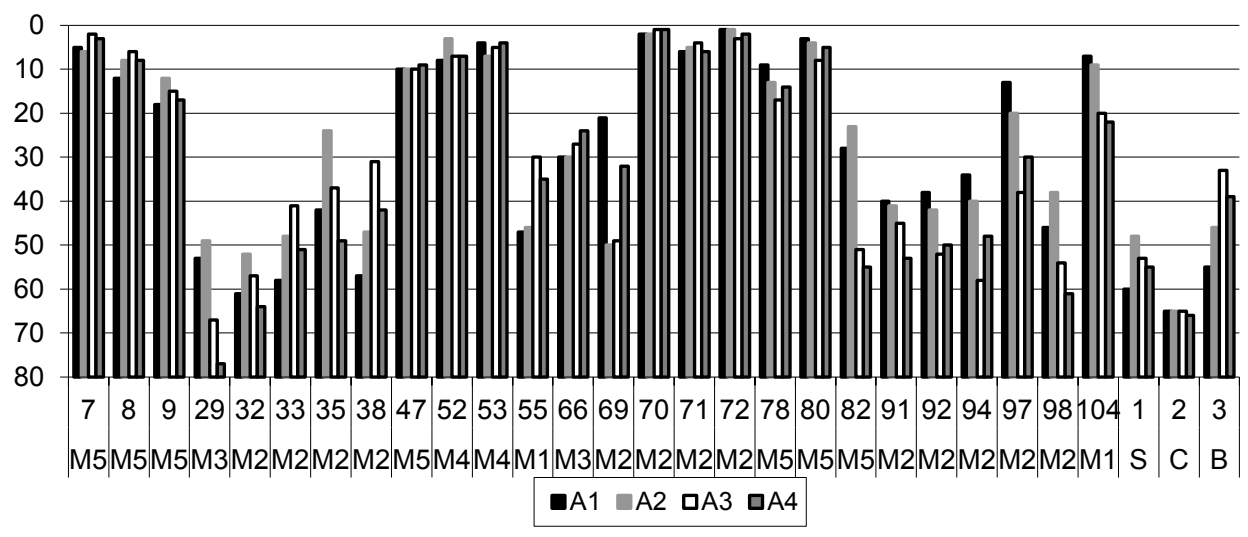

Figure 1. Ranks (vertical axis) of the selected breeding lines (horizontal axis - number of line and location of parentage or first letter of name of control variety) according to models of analysis of variance in the PW trials

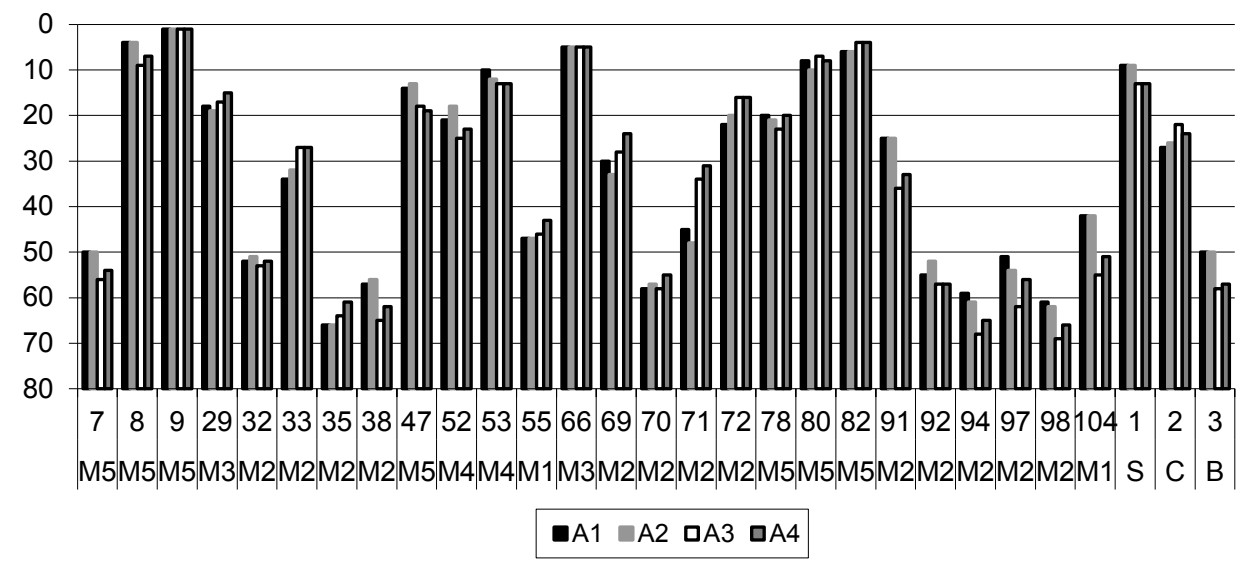

Figure 2. Ranks (vertical axis) of the selected breeding lines (horizontal axis - number of line and location of parentage) according to models of analysis of variance in the WST trials

each of the new lines (Table 3). When the A1 method was used, sometimes these contrasts were found to be significant only in one location, and then the genotype and controls were considered to be significantly different. In the case of one genotype (number 94) the contrast was significant in as many as three locations 
Table 3. Level of significance of contrasts between breeding lines and controls according to different methods of analysis of variance (for A1 there is given the number of locations at which the tested breeding line was different from the controls at the given level of significance)

\begin{tabular}{|c|c|c|c|c|c|c|c|}
\hline \multirow{3}{*}{$\begin{array}{l}\text { Location } \\
\text { of } \\
\text { parentage }\end{array}$} & \multirow{3}{*}{$\begin{array}{l}\text { Bree- } \\
\text { ding } \\
\text { line }\end{array}$} & \multicolumn{3}{|c|}{ pre-preliminary trials $(\mathrm{PW})$} & \multicolumn{3}{|c|}{ preliminary trials (WST) } \\
\hline & & \multicolumn{6}{|c|}{ ANOVA model } \\
\hline & & A1 & $\mathrm{A} 2$ & A3 & $\mathrm{A} 1$ & $\mathrm{~A} 2$ & A3 \\
\hline M5 & 7 & $1^{* * *} 2^{*} 4^{* * *} 5^{*}$ & $* * *$ & $* *$ & $1^{*} 3^{* *}$ & * & NS \\
\hline M5 & 8 & $4^{* * *} 5^{* * *}$ & $* *$ & $*$ & $3^{* * *}$ & $* * *$ & NS \\
\hline M5 & 9 & $4^{* * *}$ & * & NS & $1^{* * *} 2^{* *} 3^{* *} 4^{*} 5^{* * *}$ & $* * *$ & $* * *$ \\
\hline M3 & 29 & NS & NS & NS & $3^{*} 5^{* *} 6^{* *}$ & NS & NS \\
\hline M2 & 35 & $1^{* * *} 4^{*}$ & NS & NS & $1^{* *} 2^{* *} 4^{* *}$ & $* * *$ & $* *$ \\
\hline M2 & 38 & $1^{*}$ & NS & NS & $1^{* * *} 4^{*} 6^{*}$ & $* * *$ & $* *$ \\
\hline M5 & 47 & $5^{*}$ & $*$ & NS & NS & NS & NS \\
\hline M4 & 53 & $1^{* * *} 5^{*}$ & $* *$ & NS & $4^{* *}$ & $*$ & NS \\
\hline M1 & 55 & NS & NS & NS & $4^{*} 6^{*}$ & $*$ & NS \\
\hline M3 & 66 & $1^{* *} 5^{* *}$ & NS & NS & $4^{* *} 5^{*}$ & $* *$ & $* *$ \\
\hline M2 & 70 & $1^{* * *} 3^{* * *}$ & $* * *$ & $*$ & $1^{* * *} 3^{*} 5^{*}$ & $* * *$ & NS \\
\hline M2 & 71 & $1^{* * *} 3^{*}$ & $* *$ & $*$ & $1^{*} 6^{* *}$ & $*$ & NS \\
\hline M2 & 72 & $1^{* * *} 5^{* * *}$ & $* * *$ & $*$ & NS & NS & NS \\
\hline M5 & 78 & $1^{* * *}$ & $* *$ & $*$ & $4^{* *} 5^{*} 6^{*}$ & NS & NS \\
\hline M5 & 80 & $1^{* * *} 3^{*}$ & $* * *$ & $* * *$ & $1^{* *} 5^{*}$ & $*$ & $*$ \\
\hline M5 & 82 & $3^{*}$ & NS & NS & $6^{*}$ & $* *$ & $* *$ \\
\hline M2 & 94 & $1^{*} 2^{*} 3^{* *}$ & NS & NS & $1^{* * *} 2^{*}$ & $* * *$ & $* * *$ \\
\hline M2 & 97 & $1^{* *}$ & NS & NS & NS & $* *$ & $*$ \\
\hline M2 & 98 & NS & NS & NS & $2^{*} 3^{*} 6^{*}$ & $* * *$ & $* * *$ \\
\hline M1 & 104 & $1^{* *}$ & $* *$ & $* *$ & $4^{*} 6^{*}$ & NS & NS \\
\hline
\end{tabular}

$*, * *, * * * ;$ significance at level $0.05,0.01,0.001$ respectively;

$1,2,3,4,5,6$ - locations at which significant differences were found; NS - insignificant differences.

(method A1 in the PW trial), but according to other methods - A2 and A3 (in which the effect of location was eliminated) - the contrast was not statistically significant. The previously mentioned breeding lines 8 and 80 most often differ significantly from the controls in both years of the study (Table 3), and in both years they yielded better than the controls (Figure 1 and 2). In the first year breeding line 72 was significantly different from the controls (Table 3), and had 
the highest yield (Figure 1) according to models A1 and A2 and nearly the highest according to models A3 and A4, while in the second year it was not significantly different from the controls (see Figures 1, 2 and Table 3).

As mentioned above, the ranks obtained by the different models (A1-A4) were similar in a given year. Thus the correlation coefficient of ranks was determined in order to assess the degree of similarity of those ranks separately in each year of the study (Table 4). The results showed all of the methods to be significantly correlated ( $r_{\text {crit }}=0.2907$ critical value).

Table 4. $p$-value of rank correlation coefficients (Spearman)

\begin{tabular}{|c|c|c|c|c|c|c|c|c|c|c|c|}
\hline \multicolumn{7}{|c|}{ Between methods in the given year } & \multicolumn{5}{|c|}{ Between methods in the different years } \\
\hline Year & & 2011 & & & 2012 & & Year & & & 11 & \\
\hline Method & A1 & A2 & A3 & A1 & A2 & A3 & & A1 & A2 & A3 & A4 \\
\hline $\mathrm{A} 1$ & & & & & & & & .1088 & .1255 & .1899 & .1416 \\
\hline A2 & $<.0001$ & & & $<.0001$ & & & & .1229 & .1124 & .1734 & 1419 \\
\hline A3 & $<.0001$ & $<.0001$ & & $<.0001$ & $<.0001$ & & 2012 & .1052 & .2035 & .1683 & .0886 \\
\hline A4 & $<.0001$ & $<.0001$ & $<.0001$ & $<.0001$ & $<.0001$ & $<.0001$ & & .0844 & .2013 & .1512 & .0710 \\
\hline
\end{tabular}

The models of analysis were also compared as regards contrasts of breeding lines versus controls. For this purpose the kappa ( $\boldsymbol{\kappa}$ ) coefficient (Stehman 1992) was used (this coefficient is used in assessing the agreement of judges - in this study the judges were models A1-A4). For this purpose breeding lines which did not differ significantly from the controls were designated by zero, lines which differed significantly from the controls and yielded better than the average of the controls were designated by one, and those which yielded worse than the controls were designated by minus one. The $\kappa$ coefficient took values from -1 to 1 , and was interpreted as follows: $(-1 ; 0]$ - no agreement; $(0 ; 0.2]$ - very poor agree-ment; $(0.2 ; 0.4]$ - fair; $(0.4 ; 0.6]$ - moderate; $(0.6 ; 0.8]$ - substantial; $(0.8 ; 0.99]$ - almost perfect; 1 - perfect (Wieringen and Heuvel 2005). In the case of method A4 these contrasts could not be determined, because analysis of variance was not used in that case. Substantial agreement was obtained in both trials (PW and WST) between methods A3 and A2 (Table 5). The results presented in Tables 4 and 5 are not in complete correspondence. This may be due to the fact that in the case of 
method A1 breeding lines were taken to be significantly different from the controls if the contrast was significant at even one location.

Table 5. Kappa coefficients

\begin{tabular}{|c|c|c|c|c|c|c|c|c|}
\hline \multirow{3}{*}{$\begin{array}{l}\text { Year } \\
\text { Method }\end{array}$} & \multicolumn{4}{|c|}{ Between methods in the given year } & \multicolumn{4}{|c|}{ Between methods in the different year } \\
\hline & \multicolumn{2}{|c|}{2011} & \multicolumn{2}{|c|}{2012} & \multirow[t]{2}{*}{ Year } & \multicolumn{3}{|c|}{2011} \\
\hline & A1 & A2 & A1 & A2 & & A1 & A2 & A3 \\
\hline A1 & & & & & & .07 & -.01 & -.05 \\
\hline A2 & .430 & & .495 & & 2012 & .07 & .08 & .10 \\
\hline A3 & -.207 & .738 & -.011 & .630 & & .05 & .07 & .07 \\
\hline
\end{tabular}

When each of the years of the study was considered separately, the ranks assigned to breeding lines were arranged in a similar order; however, the results based on the agreement coefficient showed a total lack of agreement between methods A1 and A3 in both years of the study (PW and WST).

A comparison of methods of analysis between years was performed only for those breeding lines which were tested in both years. For this purpose new ranks were assigned, among only the selected breeding lines (44). On the basis of this new ranking, correlation coefficients and coefficients of agreement between years (Table 4 and 5 right side) were calculated. Between years, a non-significant correlation coefficient was obtained. Similarly, all of the coefficients of agreement indicated either lack of agreement or very poor reliability, even if the same method of analysis was used. The studied breeding lines were not stable as regards yield in the different years of the trial (they were not resistant to various environmental conditions).

Due to the lack of agreement between the results obtained in the two years of the study, the choice of the best yielding lines was a very difficult task. Therefore it seems reasonable to choose those genotypes which obtain quite high, but not necessarily the highest, rank in both years. Ranks of genotypes can be presented on a plane with respect to two years (Figure 3). Then genotypes lying on a straight line (or very close to that line) should be selected. Moreover, all genotypes located in the upper right corner should also be taken into account 


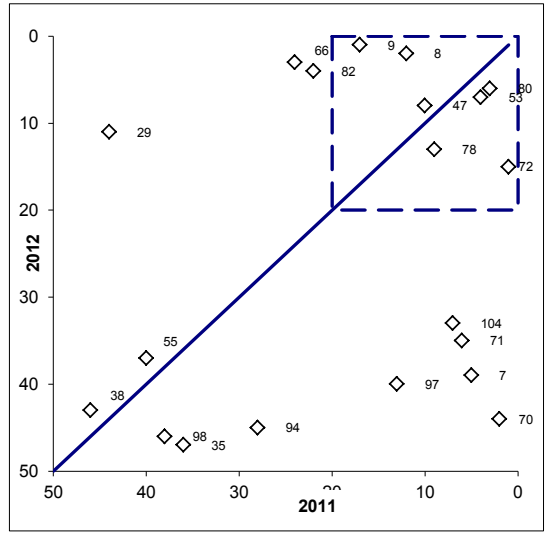

Method 1

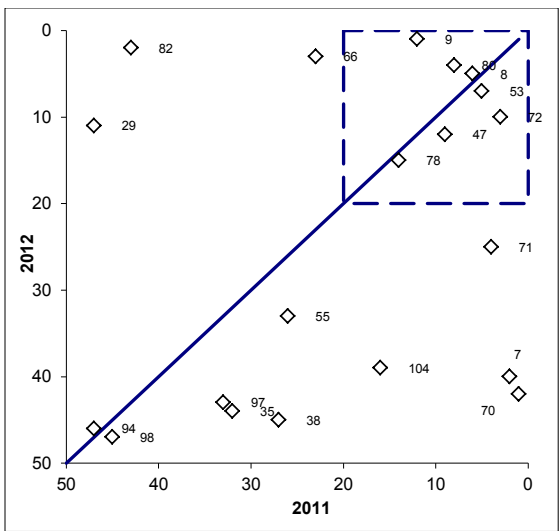

Method 3

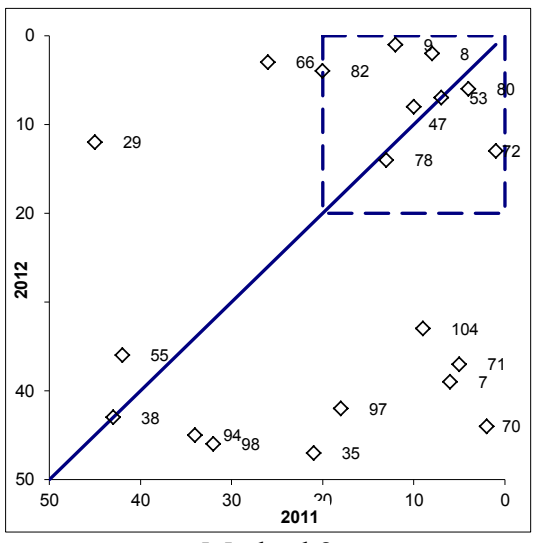

Method 2

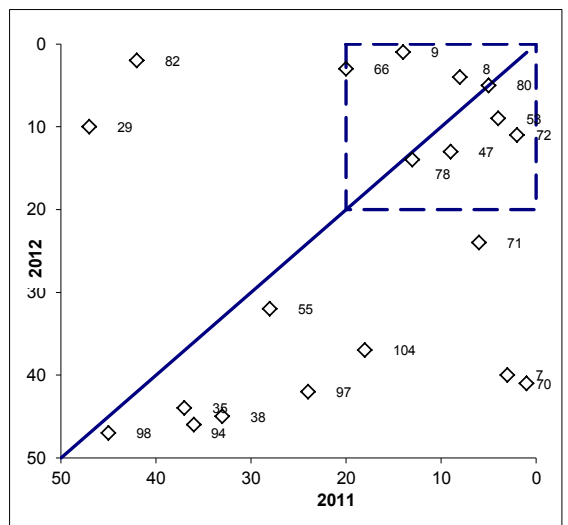

Method 4

Figure 3. Position of genotypes in terms of rank (vertical axis - rank in year 2012; horizontal axis - rank in year 2011)

because these genotypes achieve the high yield. The number of such genotypes was dependent on the model. Considering the genotypes which, in both years, achieved a rank no lower than 20 (in Figure 3, the square indicated by the dashed line) ten genotypes would be selected by method A1 (near line: 80, 53, 47, 78, 87 and 31; other genotypes lying in the square: $8,9,52,72$ ), A2 (near line: 80,53 , 47,78 ; other genotypes lying in the square: $8,9,52,72, \mathbf{8 2}, \mathbf{3 1}$ ) and $\mathrm{A} 3$ (near line: $8,80,53,47,78$; other genotypes lying in the square: $9,72,87,52,83)$, while 
eleven genotypes would be selected by method A4 (near line: 8, 80, 87, 47, 78; other genotypes lying in the square: $53,72,9,52,83,66)$.

\section{Discussion and conclusions}

At breeding stations, trials are often analyzed using method A1. Nested analysis (A2) is also used, but breeding lines are not compared on the basis of the results of such analysis. Węgrzyn (2001) proposed analysis of series trials, for example PPI, PPII, and PB and multi-location trials, using a cross design. In model A1 the trials conducted at the particular locations were still considered separately. The best method for the experimental design used in breeding trials is A2, in which the variability between environments is eliminated from the general variability, making it easier to detect differences between the studied lines. Similar analysis, as in A2, was presented by Emede and Alika (2012). The use of mixed models for analysis of series of variety trials was described by Kempton (1984); later Smith et al. (2005) considered individual methods in detail. Piepho (1997) employed a mixed model analogue of PCA for the analysis of MET data. Methods of analysis of trials conducted at several locations (hierarchical) should be applied more extensively. The correlations between the rankings of the methods presented in this paper did not differ significantly. However, even small changes may affect the selection of genotypes. This is clearly noticeable when the coefficients of agreement between the methods are considered. Separate analysis of experiments in successive years of study caused another dilemma for breeders, because the tested lines were ranked in different positions. Here, the problem of the instability of genotypes in successive years of study has already been noted. The same trend appeared in a study by Węgrzyn (2001). In this study a complete lack of conformity of results between years, on the basis of both rank correlation and coefficient of agreement, was demonstrated.

The combined analysis of several years of trials may help breeders to make choices. However, new lines can be reported for registration testing after only one 
year of research at breeding stations, hence many of them have not been examined in preliminary experiments, which hinders the analysis to a significant degree.

This study on the performance of some ANOVA models led to the same conclusions. Results obtained on the basis of the various methods of analysis were similar within years. Significant differences in the ranking of breeding lines were shown between years (environmental variability in the different years had a large impact on yields). Some better breeding lines in 2011 were among the weakest lines in the following year (for example, lines 7 and 70) while some lower yielding lines in 2011 had better yields in 2012 (lines 29 and 1; see Figure 3). The analysis helped to detect differences which occurred between breeding lines in given environments. It is very important for plant breeding to consider the occurrence of lines with both high and low genotype-environment interaction. Based on rank correlation (Table 4) it can be stated that the results obtained from methods based on averages (A3) differed quite significantly from results based on all observations (the lowest correlation coefficients were between these methods and methods A1 and A2). Based on the agreement coefficient, substantial agreement was found only for method A3 with method A2 (Table 5) - of course, only within the same year. Method A4 was strongly correlated only with the method based on averages: A3. Among the models of analysis of variance, the most useful in selecting lines for further trials appears to be a more extensive method such as A2, in which environmental variability is taken into consideration.

The results presented here lead to the overall conclusion that the choice of ANOVA model may have an impact on inferences concerning breeding lines. Moreover, the impact of years on the yield of genotypes has been shown. Thus it is important for breeding trials to be conducted over at least two years. Moreover, all years of the trials should be jointly analyzed, taking into account the effect of years in ANOVA. This problem is related to the stability of breeding lines and varieties over years, and to genotype-year interaction (see Fan et al., 2007; Alghamdi, 2004). 
It is worth paying particular attention to the genotypes with relatively high ranks lying on the straight line which means that they have high yield (high rank) in both years (Figure 3). Moreover, very interesting were genotypes which changed from one extreme to the opposite extreme (e.g. low yield in the first year and high yield in the second).

\section{REFERENCES}

Alghamdi S.S. (2004): Yield stability of some soybean genotypes across diverse environment. Pakistan Journal of Biological Sciences 7: 2109-2114.

Allard R.W. (1999): Principles of Plant Breeding. John Wiley Publishing, New York.

Bystry Z., Adamska E., Rybiński W. (2005): Evaluation of breeding lines of malting barley based on the results of a pre-registration trial (in Polish: Ocena rodów jęczmienia browarnego na podstawie wyników doświadczenia wstępnego). Biuletyn IHAR 235: 139-145.

Elandt R. (1964): Statistics in experimental agriculture (in Polish: Statystyka matematyczna w zastosowaniu do doswiadczalnictwa rolniczego). PWN, Warszawa.

Emede T.O., Alika J.E. (2012): Variation in agronomic characters among high and low nitrogen S2 maize (Zea mays L) lines grown in high and low nitrogen environments. Maydica 57: 139-146.

Fan X.M., Kang M., Chen H., Zhang Y., Tan J., Xu C. (2007): Yield stability of maize hybrids evaluated in multi-environment trials in Yunnan China. Agronomy Journal 99: 220-228.

Kempton R.A. (1984): The use of biplots in interpreting variety by environment interactions. Journal of Agricultural Science, Cambridge 103: 123-135.

Montgomery D.C. (2000): Design and Analysis of Experiments, Wiley (5th Edition).

Piepho H.P. (1997): Analyzing genotype-environment data by mixed models with multiplicative terms. Biometrics 53: 761-767.

Smith A.B., Cullis B.R., Thompson R. (2005): The analysis of crop cultivar breeding and evaluation trials: an overview of current mixed model approaches. Journal of Agricultural Science 143: 449-462.

Stehman S.V. (1992): Comparison of systematic and random sampling for estimating the accuracy of maps generated from remotely sensed data. Photogrammetric Engineering \& Remote Sensing 58: 1343-1350.

Węgrzyn S. (2001): An application of some statistical methods in plant breeding trials (in Polish: Możliwości wykorzystania metod statystycznych do opracowania wyników doświadczeń w hodowli roślin). Biuletyn IHAR 218/219: 5-14.

Wieringen W.S., Heuvel E.R. (2005): A Comparison of Methods for the Evaluation of Binary Measurement Systems. Quality Engineering 17: 495-507. 